Images in...

\title{
An unusual sore finger...
}

\author{
D Mrabet, ${ }^{1}$ S Rekik, ${ }^{1}$ M Ounais, ${ }^{2}$ S Trojet, ${ }^{3}$ I Zaraa, ${ }^{3}$ N Meddeb, ${ }^{1}$ A Ben Osmane, ${ }^{3}$ L Tarhouni, \\ H Sahli, ${ }^{1}$ S Sellami ${ }^{1}$
}

1Department of Rheumatology, La Rabta Hospital, Tunis, Tunisia;

2Department of Hand Surgery, Ksar Said Hospital, Manouba, Tunisia;

${ }^{3}$ Department of Dermatology, La Rabta Hospital, Tunis, Tunisia

Correspondence to D Mrabet, mrabetdalila@yahoo.fr

\section{DESCRIPTION}

We describe the case of a 75-year-old man with a history of chronic lymphoid leukaemia stage B in Binet system treated by chemotherapy with chlorambucil and prednisolone. The patient was in complete remission with this treatment for 3 years. When he presented to our department, he complained of two painful and indurated swellings in the right fifth finger and in the right wrist that had appeared 7 months before (figures $1 \mathrm{~A}$ and B). Blood tests showed increased erythrocyte sedimentation rate and $C$ reactive protein level with a normal white cell count. Tests for rheumatoid arthritis factor, hepatitis B and C viruses, HIV, brucella and Salmonella typhi were negative. Mantoux tuberculin skin test showed an induration of $34 \mathrm{~mm}$ after $72 \mathrm{~h}$. A tuberculous infection was suspected but bronchoalveolar lavage and mycobacterium culture was negative. A surgical synovectomy was performed and macroscopic findings revealed numerous white nodules that appeared like scattered grains of boiled rice (figure 2). Histopathological examination of the biopsy specimen revealed granulomatous inflammation with caseous necrosis (figure 3 ). The diagnosis of tuberculous dactylitis was established and treatment was initiated with four drugs (rifampicine, ethambutol, isoniazide and pyrazinamide) for 2 months followed by two drugs (rifampicine and isoniazide) for 6 months. The swelling disappeared and dactylitis was cured 6 months after initiation of antitubercular treatment.

\section{DISCUSSION}

Metacarpals and phalanges are unusual sites for extrapulmonary tuberculosis. This rare aetiology of dactylitis must be kept in mind and should be considered in patients suffering from chronic lesions, especially in immunocompromised patients.

Tuberculous dactylitis (TD) is difficult to diagnose as it is difficult to distinguish from other lesions. To make the correct diagnosis of TD during an early stage it is crucial that physicians are aware of this disease. There are no typical clinical signs and symptoms. Specific investigations and radiographical findings must first rule out sarcoidosis dactylitis and gout. Then, the differential diagnosis may be required between TD and other joint diseases, such as inflammatory arthritis, especially rheumatoid arthritis, which may exhibit cystic changes, and between TD and malignant neoplasm (Kaposi's sarcoma) or benign tumour (haemangioma or enchondroma). Culture and early biopsy with appropriate microbiological testing can provide an earlier diagnosis. Diagnosis lag can have serious consequences. It is very important that patients recover a full range of motion as soon as possible to prevent joint contracture and subsequent ankylosis.
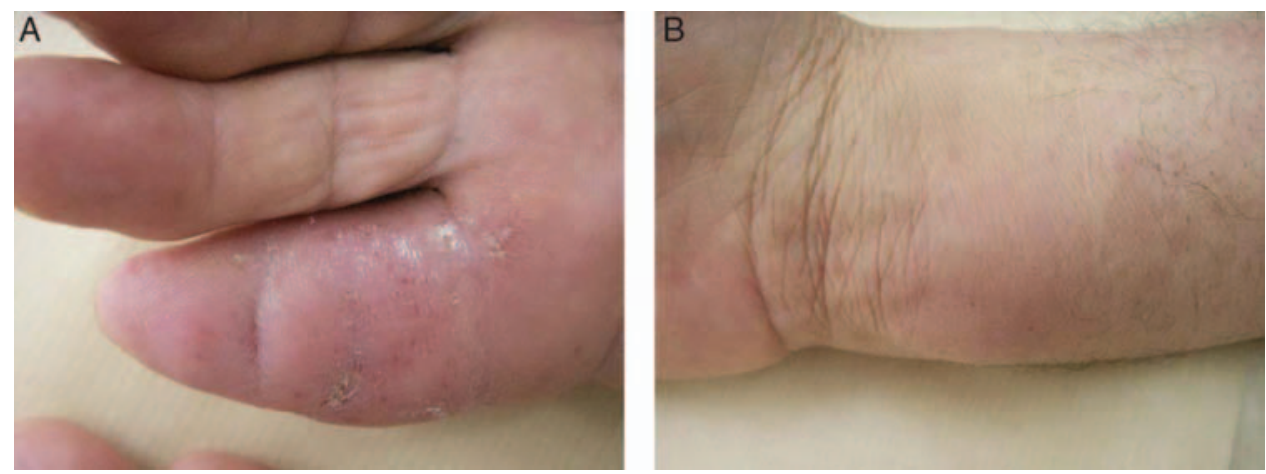

Figure 1 (A) Right fifth finger: marked swelling and induration of the finger. (B)Right wrist: marked swelling and induration of the wrist. 


\section{BMJ Case Reports}

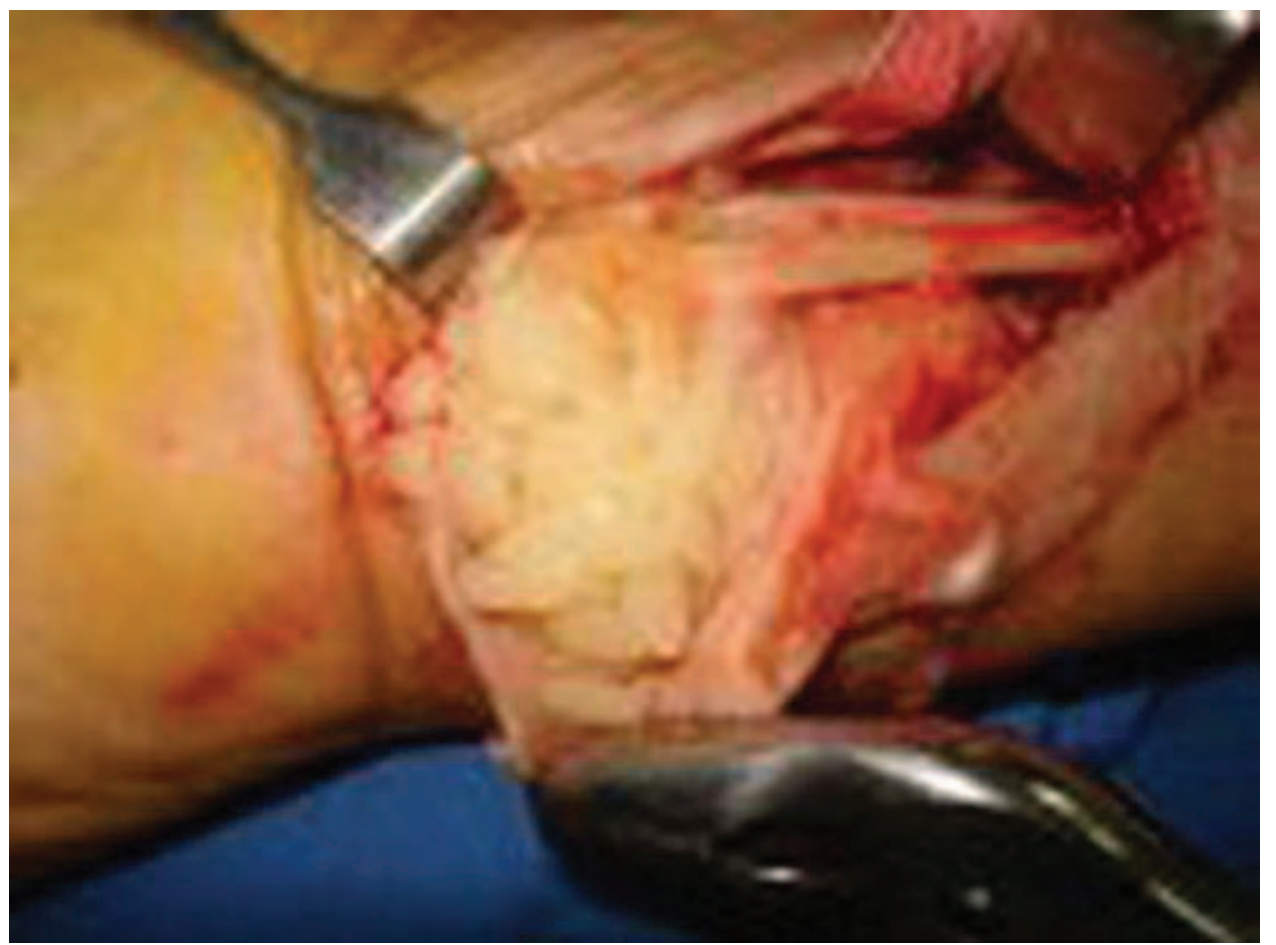

Figure 2 Perioperative view of the wrist's tenosynovitis: numerous rice grain like bodies.

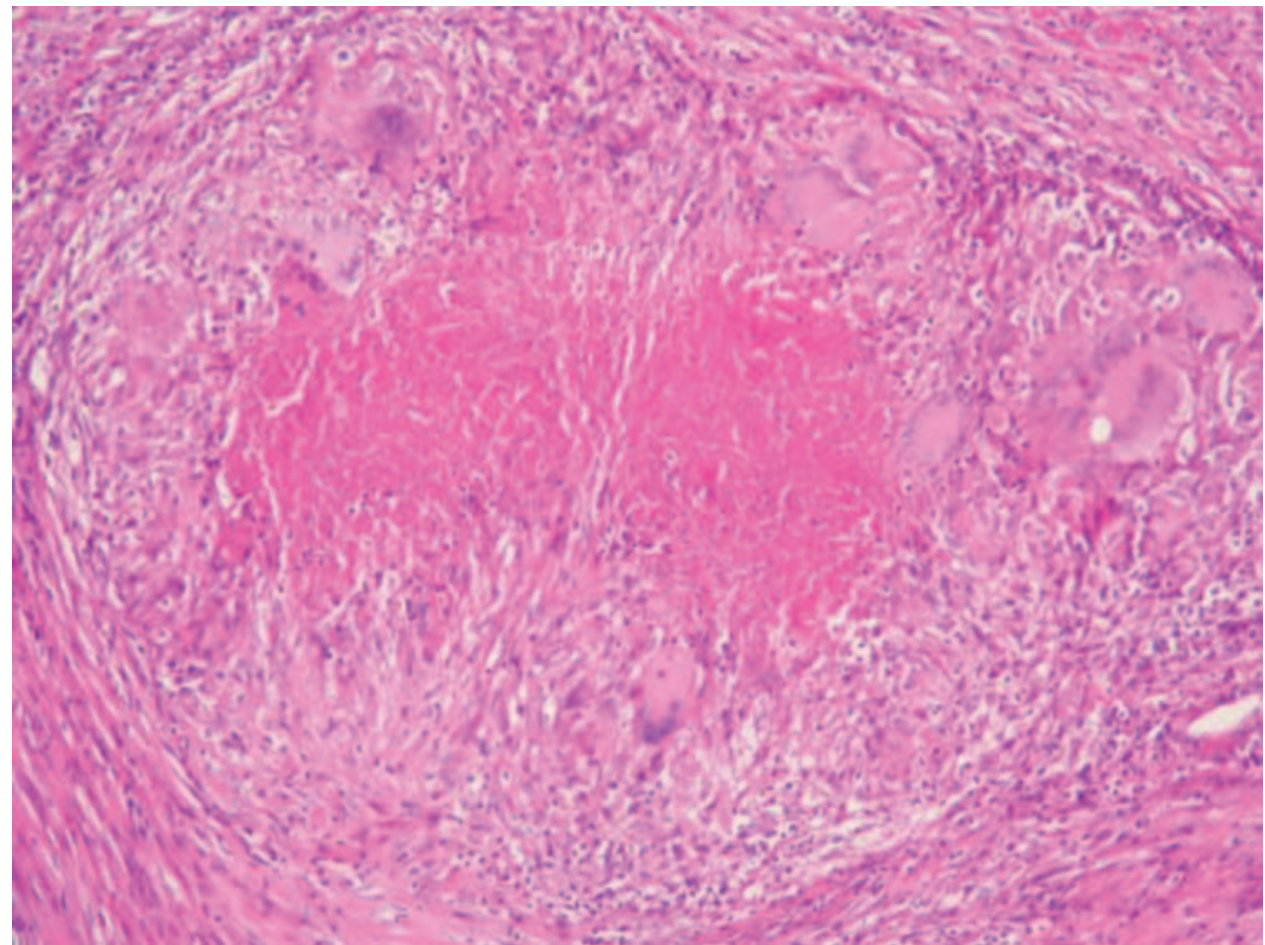

Figure 3 Synovial biopsy (H\&E400): granulomatous inflammation with caseous necrosis.

\section{Competing interests None.}

Patient consent Obtained.

\section{REFERENCES}

1. Chowdhary V, Aggarwal A, Misra R. Multifocal tubercular dactylitis in an adult. J Clin Rheumatol 2002;8:35-7.
2. Agarwal S, Caplivski D, Bottone EJ. Disseminated tuberculosis presenting with finger swelling in a patient with tuberculous osteomyelitis: a case report. Ann Clin Microbiol Antimicrob 2005;4:18.

3. Huang GS, Lee $\mathrm{CH}$, Chen CY. Clinical images: Tuberculous rice bodies of the wrist. Arthritis Rheum 2005;52:1950. 


\section{BMJ Case Reports}

This pdf has been created automatically from the final edited text and images.

Copyright 2011 BMJ Publishing Group. All rights reserved. For permission to reuse any of this content visit http://group.bmj.com/group/rights-licensing/permissions.

BMJ Case Report Fellows may re-use this article for personal use and teaching without any further permission.

Please cite this article as follows (you will need to access the article online to obtain the date of publication).

Mrabet D, Rekik S, Ounais M, Trojet S, Zaraa I, Meddeb N, Osmane AB, Tarhouni L, Sahli H, Sellami S. An unusual sore finger.... BMJ Case Reports 2011;

10.1136/bcr.11.2010.3503, date of publication

Become a Fellow of BMJ Case Reports today and you can:

- Submit as many cases as you like

- Enjoy fast sympathetic peer review and rapid publication of accepted articles

- Access all the published articles

- Re-use any of the published material for personal use and teaching without further permission

For information on Institutional Fellowships contact consortiasales@bmjgroup.com

Visit casereports.bmj.com for more articles like this and to become a Fellow 